\title{
Sixteen level power factor correction by using arduino microcontroller based fuzzy idea
}

\author{
Osama Qasim Jumah Al-Thahab, Ali Shaban hasoony, Ahmed Samawi Alkhafaji \\ Department of Electrical Engineering, College of Engineering, University of Babylon, Iraq
}

\begin{abstract}
Article Info
Article history:

Received May 30, 2019

Revised Jul 1, 2019

Accepted Jul 15, 2019

\section{Keywords:}

Arduino uno

Capacitor bank

Comparator

Fuzzy logic algorithm

PFC system

Relays

ABSTRACT

Nowadays, a controller that improves the power factor (PF) is automatically designed and implemented to correct the value of the power factor once they falls below a certain one. In industry, day by day, there is an increase in the use of domestic applications and inductive loads such that they consider the essential reason whose responsible on lowering the power factor. Therefore a development method is needed to improve the power factor by adding manually variable capacitors or automatically. Fuzzy algorithm can be used as an intelligent system to estimate the value of the capacitor that should be added to compensate the effect of inductors. In this work, sixteen level of power factor are corrected automatically by new way through using Arduino Uno that programed with the aid of Fuzzy logic idea. A bank of four capacitors with different values is used and the Fuzzy helps taking the decision of which capacitors be ON or OFF. Here, the correction of power factor is from 0.64 to 0.98 , and each level gives an increment of 0.02125 in PF. The experimental results are very close to the theoretical one, and the cost is very acceptable since the circuit is built from cheap equipments such as Arduino, potential transformer, relays, zero crossing circuit and current transformer. In addition, the maximum error due to the difference between the capacitor theoretical calculation and the practical is about $4.1 \%$, while the error between the desired and the result value of PF is about $4.08 \%$ for maximum.
\end{abstract}

Copyright $@ 2020$ Institute of Advanced Engineering and Science. All rights reserved.

\section{Corresponding Author:}

Osama Qasim Jumah Al-Thahab,

Department of Electrical Engineering,

Babylon University,

Al-Hilla, Babylon, Iraq.

E-mail: osamaalthahab@gmail.com.

\section{INTRODUCTION}

The common issue in everyday life is the energy saving, so when the price of energy be high, the devices that reduce the consumption of energy consider very important. Voltage and current are the acquired quantities that are directly proportional to energy saving efficiency, so for successive processing these quantities are essential [1]. The AC system power quality becomes very important, since there is increase in electronic equipment numbers, power electronics in addition to high voltage power system. In our country, most of industrial installation and commercials have large electrical loads, which makes the power factor lagged because they are inductive in nature [2]. At inductive loads, the useful work is done by the active power while the reactive one returns to the source on current cycle, since it dissipates no energy in the load. This may reduce the consumer side voltage because of the high requirement of the reactive power [3], consequently, the continuous load Power Factor monitoring is very essential. When PF falls below a specified value, the line current increases, making the line loss and voltage drop increase too [4]. The device with power factor correction (PFC) circuit would return the system power factor near the unity for economical operation. Adding this device will give advantages to the whole system includes: improved 
voltages, increased load-carrying capabilities, reduced losses of power system, and reduced the drop in voltage along the cables [5].

There are many different ways on how to measure the PF and the modern one is the use of microcontroller (PIC Microcontroller, 8051 microcontroller, AT89S52 microcontroller or Arduino). In order to compensate the excessive reactive power, suitable capacitors are locally add, thus almost unity power factor can satisfy. A microcontroller helps in sensing the change of power factor and choosing which a suitable capacitor should be selected from the capacitor bank [6-9].

M. Vishvanath and his team [10] produce a new bidirectional bridgeless LUO converter used in the main AC system. It is a DC/DC Converter which become take more attention nowadays since it increase the $\mathrm{PF}$ at the ac mains. In Bridgeless Power Factor Correction Converter (BPFCC) design there is no need for a diode bridge at the input, which minimize the power losses and enhanced the whole system efficiency and savings cost. Murugan $M$ et al [11] proposed in their paper the analyses and the design of power factor rectification based on front end bridgeless single-ended primary inductance converter (BLSEPIC), in addition to high frequency isolation and regulated of output voltage working in discontinuous conduction mode. There are many methods used in PFC systems and Cuk converter with PID controller is one of them. As compared to traditional power factor correction Cuk converter protects from the inrush current and it is combination of Buck Boost operation [12].

M. Myint Than in [13] deals with the implementation of Automatic Power Factor Correction (APFC) system using an Arduino UNO controller with the solid state Triac as a switch and a capacitor bank (four capacitors) to compensate the reactive power. Also in this field, A. Taye [14] in 2018 uses two groups of capacitors to make the PF reaching the industrial value (0.92) from (0.66). He utilizes Arduino UNO to make the decision of what group of capacitors work.

The problem statement here in our country (Iraq) is that the amounts of reactive power that produced from household appliances, offices, small institutions, rooms, or government offices, etc is small, therefore there is no need to implement a large station for PFC at the Power Plant which may coast a lot of money for the government. Also if any fault occurs, the system of PFC is automatically stopped. For those reason, an electronic device has to be designed and implemented to correct the PF automatically for a small amount of power consumption. All small stations mentioned above can benefit from this device, the reactive power problem will fixed, and consequentially the overall amount of power being use per day is reduced.

In this work, a 16 level of APFC is designed and implemented using Arduino Uno with the aid of Fuzzy logic idea to speed the analysis and give more accurate performance. The proposed system can compensate and correct a PF from 0.64 very poor, to 0.98 , near the unity, as can be seen from results.

\section{FUZZY LOGIC ALGORITHM}

A controller that uses the fuzzy logic can consider a knowledge-based controller, since it changes the equivalent navigational constant value to gather the maximum benefits in terms of the missile performance [15]. The system of Fuzzy logic may consider as a nonlinear mapping of input data group to a scalar output data. The system may include of four parts: Fuzzifier, inference engine, Rules and defuzzifier. The general architecture with fuzzy logic system components is shown in Figure 1. Generally, the objects or things that include one or more similar characteristics may be gathered and classified into a set or group, and each one contained members related to each set [16].

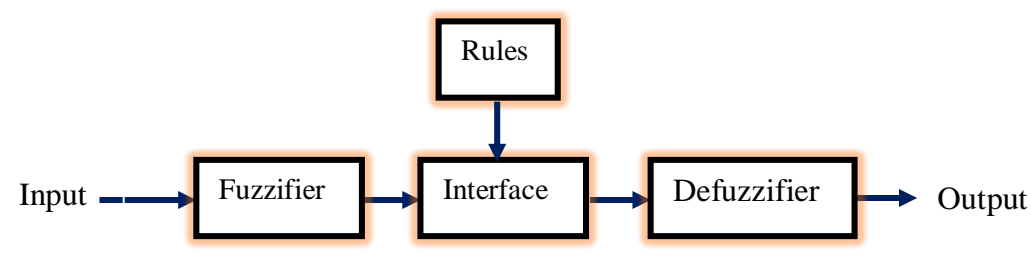

Figure 1. General fuzzy system

\section{PROPOSED ARDUINO PFC WITH FUZZY LOGIC SYSTEM}

The idea here is to design and implement a PFC device with a low cost and high precision of correction in fastest way, so that homes, offices etc can benefit from it. The proposed system calculates the power factor from the line current and line voltage through computing the delays between the arrival current signals and voltage signal from the power supply. Then the microcontroller calculates the compensation 
requirement using a Fuzzy algorithm and according to its suggestion, Arduino Uno switched on a different capacitor in the capacitor bank.

The bank of capacitors is used for improving PF from 0.64 to 0.98 with 16 level of correction. The proposed APFC system diagram is clearly seen in Figure 2. The circuit consists of zero crossing detector, potential transformer (PT) with Current transformer (CT), Arduino Uno microcontroller, capacitor bank, relay driver circuit, and inductive load.

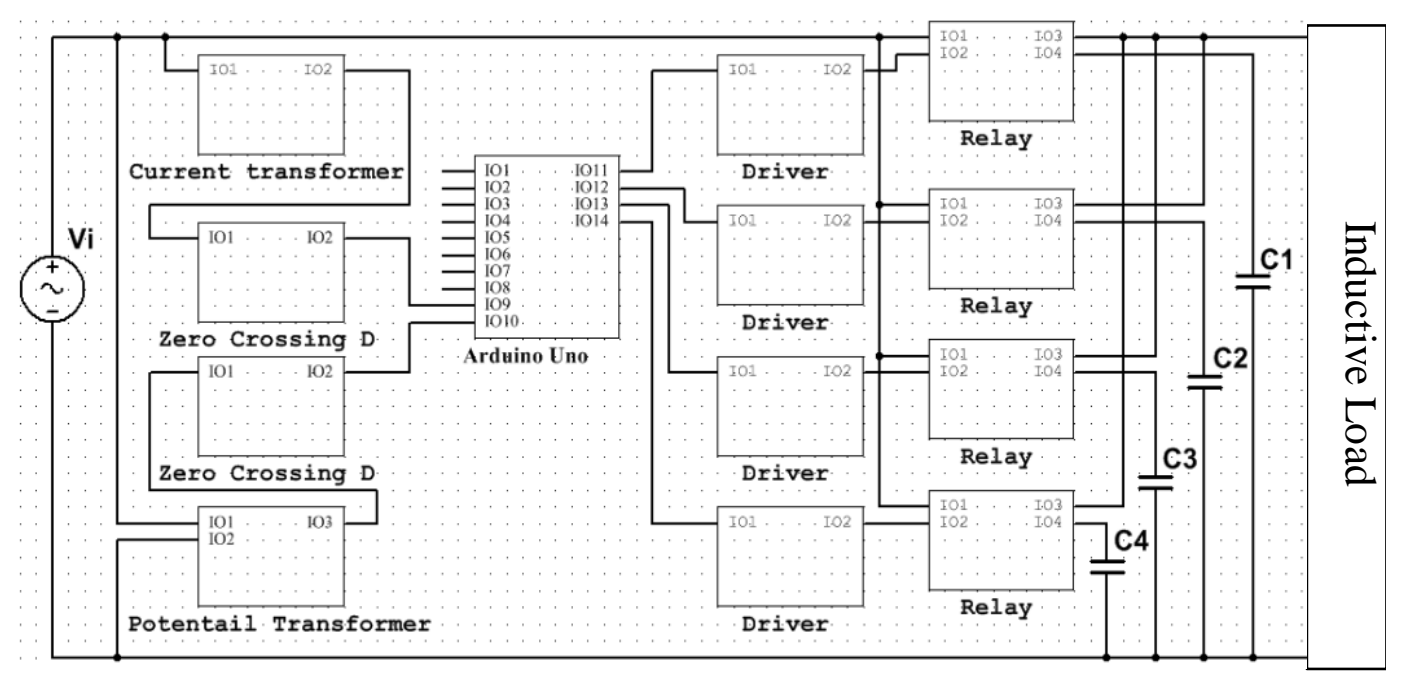

Figure 2. APFC whole circuit diagram of the proposed system

\subsection{Potential Transformer (PT) with Current Transformer (CT)}

CT is used to measure the current that passes through load, so that the input source is connected in series with the primary while the secondary is connected to the input of Zero crossing detector. Figure 3(a) states the CT that used here in this work. PT is used to obtain the value of input voltage, but in this work, a voltage divider circuit is used instead. It consists of two resisters connected in series $(100 \mathrm{k} \Omega$ and $2.48 \mathrm{k} \Omega)$ to step down the input voltage to a suitable voltage that can read by the Zero Crossing Detector. Figure 3(b) shows the Voltage Divider (VD) circuit and its implementation on Vero board.

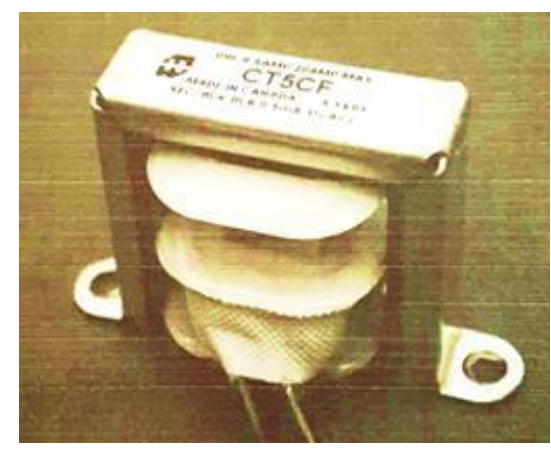

(a)

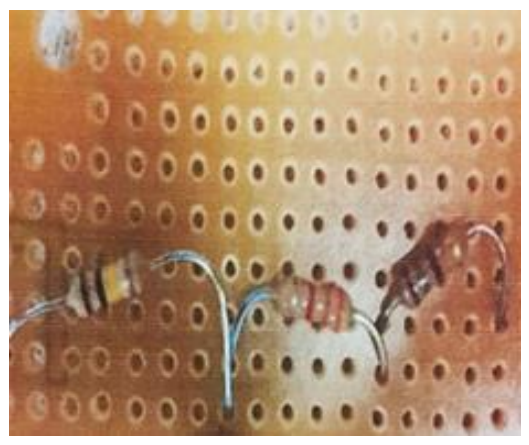

(b)

Figure 3. CT and VD circuits (a). CT (b). VD

\subsection{OP-AMP Zero Crossing Detector}

It is a traditional convertor, which transform the sine-wave signal to the square wave signal, and in this case, the reference voltage is set to be zero. Here, LM111 IC OP-MP is used in the context for both input voltage and current. The circuit design and its implementation with the waveform outputs of Oscilloscope are seen in Figure 4. The first waveform belongs to the voltage while the second one belongs to the current. The phase difference is seen between them clearly on the screen of Oscilloscope. 


\subsection{THE ARDUINO UNO MICROCONTROLLER}

Arduino Uno is one of the famous microcontrollers that has been developed recently and it uses in many applications since it is cheap and easy to program. The ATmega328 represents the base of its board. It has 6 analog inputs, 14 digital input/output (6 of them can be used as PWM outputs), a crystal oscillator with frequency of $16 \mathrm{MHz}$, a USB connection, a power jack, an ICSP header, and a reset button. It includes all things that needed for supporting the microcontroller. Arduino Uno can be connected to a battery, power supply with an AC-DC adapter or through a USB cable by using a computer to get started [17].

In this research, the Arduino is programed to calculate the phase difference between the current and voltage, and then decide which suitable capacitor must be connected with the load to enhance the PF. The decision is made by the aid of a Fuzzy algorithm, which chooses what a fuzzy group does the phase deference belongs to. The $\mathrm{C}++$ program is utilized here for programing the microcontroller (Arduino Uno), and it is downloaded to the board via USB cable. The board of Arduino Uno that used here in this work is stated in Figure 5.
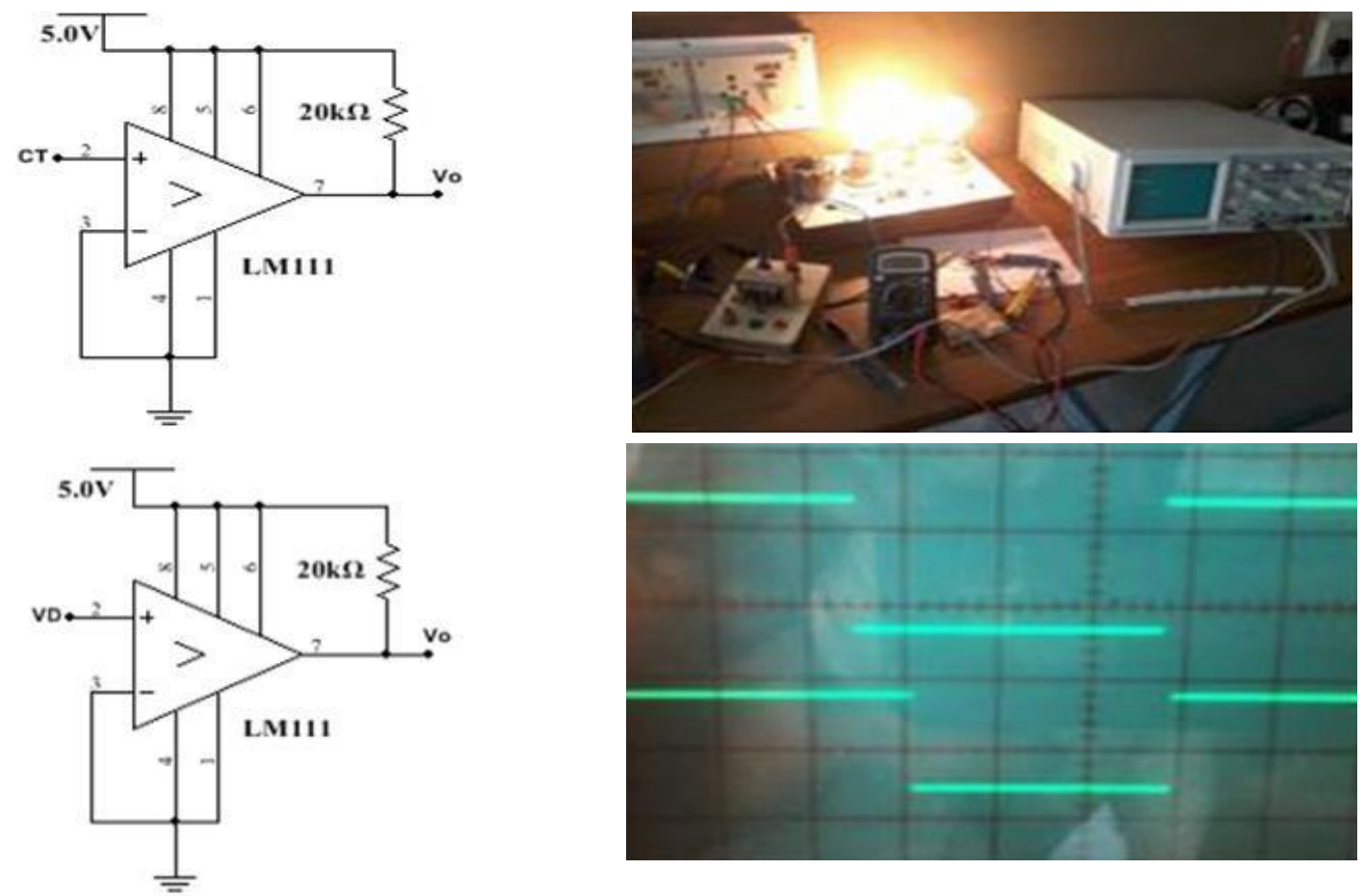

Figure 4. Zero Crossing Detector circuit with its output waveforms

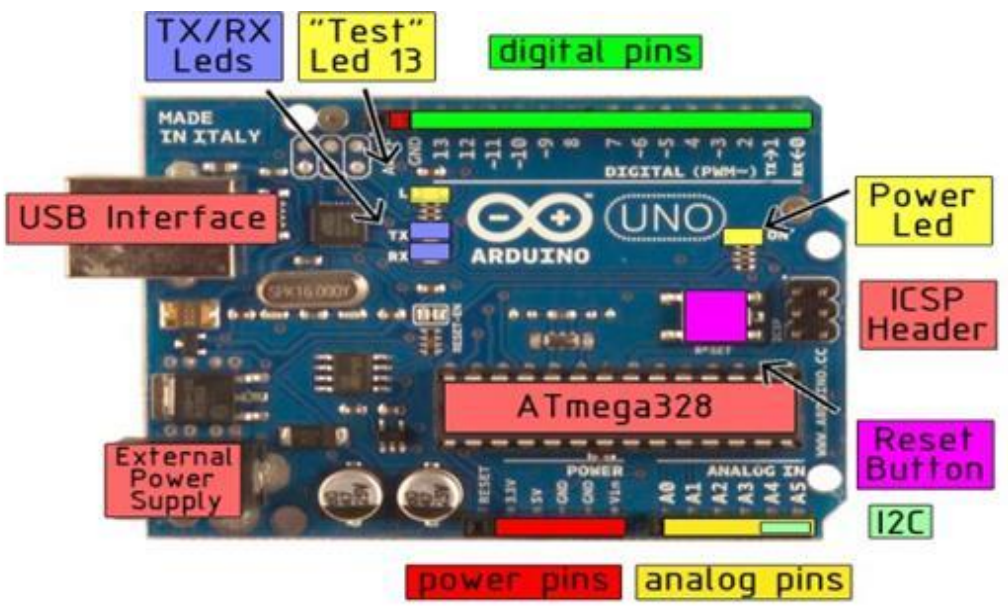

Figure 5. Arduino UNO board 


\subsection{RELAYES AND DRIVER}

Relays are used here to switch between the capacitors so that each relay can switch one capacitor, and since there are four capacitors used in this project, four relays with their drivers are needed. The output of the microcontroller turns in to the driver, which consequently makes the relay in the ON state if it is high. Otherwise, the relay is OFF. The relays with their driver board is seen in Figure 6. Another way to switch the capacitor bank can be depicted in $[13,18]$. The authors used TRIACs as a switch to correct and maintain the power factor above 0.9. However, the relays are cheaper and easier to connect and there is no need of triggering circuit or Firing control.

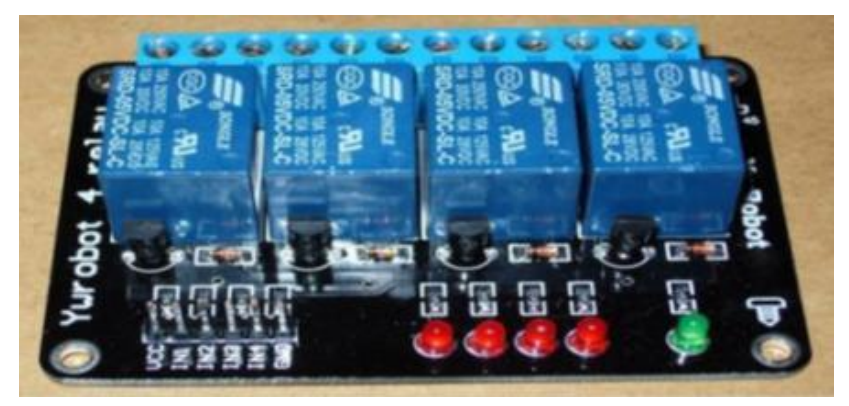

Figure 6. Relays board with their driver

\subsection{CAPACITOR BANK}

The capacitors are used generally to reduce reactive power as well as load current and, consequently, decreasing apparent power, since they give a leading power factor, so PF can be corrected. To depict the value of capacitor needs, the following equations state the relation between PF and reactive power in addition to the capacitors:

$$
\begin{aligned}
& S=V * I \\
& S=P+j Q \\
& P=S * \cos \emptyset \\
& Q=S * \sin \emptyset
\end{aligned}
$$

where $S$ is the apparent power, $I$ is the load current, $V$ is the input voltage, $P$ is the active power and the reactive power is $Q$, while $\cos \emptyset$ consider the PF. The angle $\varnothing$ considers the phase difference (the angle) between current and voltage so that when the phase difference decreases, PF increases while $Q$ decreases. The term $P$ is maintain at the same value. Figure 7 considers the relationships between $S, P, Q$ and PF.

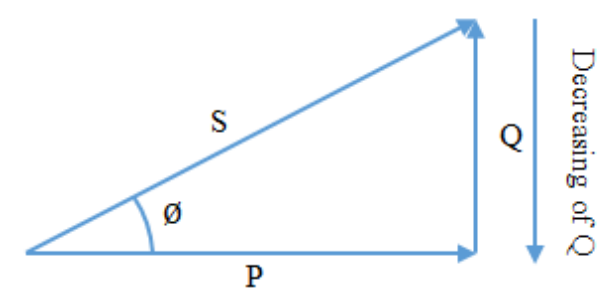

Figure 7. Trigonometric view of power factor

In this work, the proposed electronic circuit is aimed to drive a $1 \mathrm{KVA}$ variable load of different consumption power with a PF range from 0.64 to 0.98 . Other specifications are $f=50 \mathrm{~Hz}, V=(220-230) \mathrm{v}$, and $P=640$ Watt, whereas the value of the capacitor which is needed to correct the power factor can be determined from the following equations: 


$$
\begin{aligned}
& S_{1}=P / \cos \emptyset_{1} \\
& S_{1}=\frac{640}{0.64}=1000 \mathrm{VA} \\
& \emptyset_{1}=\cos ^{-1}(0.64)=50.2^{\circ}, \mathrm{so} \\
& Q_{1}=\mathrm{S}_{1} \sin \emptyset_{1}=768.37 \mathrm{VAR} \\
& \emptyset_{2}=\cos ^{-1}(0.98)=11.48^{\circ} \\
& Q_{2}=\mathrm{P} \tan \emptyset_{2} \\
& Q_{2}=640 * 0.2038=130 \mathrm{VAR} \\
& Q_{\mathrm{C}}=Q_{1}-Q_{2} \\
& Q_{\mathrm{C}}=768.37-130=638.37 \mathrm{VAR} \\
& C=\frac{Q_{C}}{2 \pi f v^{2}} \\
& C=38.3-42 \mu \mathrm{F} \text { (range) }
\end{aligned}
$$

To satisfy the sixteen levels of PF in this project, four capacitors are added in parallel to the load as seen in Figure 8
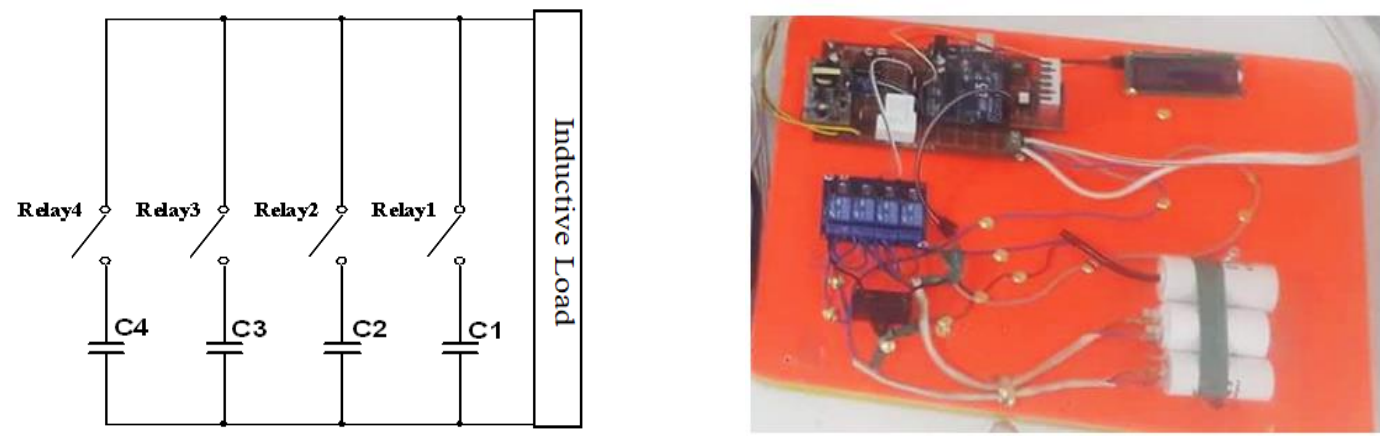

Figure 8. Capacitor bank simulation and practical implementation

The capacitor value that must be added for each level is about $38.3 \mu \mathrm{F} / 16=2.4 \mu \mathrm{F}$ to $42 \mu \mathrm{F} / 16=$ $2.625 \mu \mathrm{F}$. However, in our electronic market, there is no such value; thus, an approximate quantity can be used. Four capacitors founded in the market having the values of $(2.5,5,10$ and 20) $\mu \mathrm{f}$ will be used and connected in parallel to the inductive load through four relays as seen in figure 8 . This process gives $\left(2^{4}\right)$ different capacitor levels as depicted in Table 1.

Table 1. The Range of Capacitor Level According to Relay open-close

\begin{tabular}{ccccc}
\hline Realy1 & Realy2 & Realy3 & Realy4 & Capacitor $(\mu \mathrm{F})$ \\
\hline Off & Off & Off & Off & 0 \\
On & Off & Off & Off & 2.5 \\
Off & On & Off & Off & 5 \\
On & On & Off & Off & 7.5 \\
Off & Off & On & Off & 10 \\
On & Off & On & Off & 12.5 \\
Off & On & On & Off & 15 \\
On & On & On & Off & 17.5 \\
Off & Off & Off & On & 20 \\
On & Off & Off & On & 22.5 \\
Off & On & Off & On & 25 \\
On & On & Off & On & 27.5 \\
Off & Off & On & On & 30 \\
On & Off & On & On & 32.5 \\
Off & On & On & On & 35 \\
On & On & On & On & 37.5 \\
\hline
\end{tabular}




\section{RESULTS WITH THEIR DISCUSSION}

The implementation of the proposed APFC system is clearly stated in Figure 9, which consist of control circuit, three motors and fan as a load. The maximum power of them is 630 watt with power factor of 0.78. Also four capacitors $(2.5,5,10$ and 20) $\mu \mathrm{f}$ are exist to compensate the reactive power. In addition, LCD is used to display all readings of load current, voltage, power and PF.

Here, there are sixteen levels of PF from 0.64 to 0.98 to be corrected. Each one has a value of $(0.34 / 16=0.02125)$, so that the first value to be corrected is 0.64 , which needs the max value of the capacitor bank, while the second value is 0.66125 and so on. For example, if the power factor is 0.9, the Fuzzy program inside the Arduino will decide the group that 0.9 belongs to, and in this case, it belongs to the group of (0.895-0.91625) PF. Then a signal will sent to the relays for selecting the corresponding capacitors.

Table 2 shows the levels of PF with their theoretically and practically corresponding capacitors in addition to the error between them. After that, the program re-monitors the new readings of the power, current, voltage and new power factor, then takes a new decision and so on. The results for different power factor with different loads are shown in Table 3, in which a switch plug can select the load. Here, there are four switch plugs as you can see in Figure 9, so that each one is connected to single load, therefore, if you want to get a certain load, you may choose the suitable switch to close.

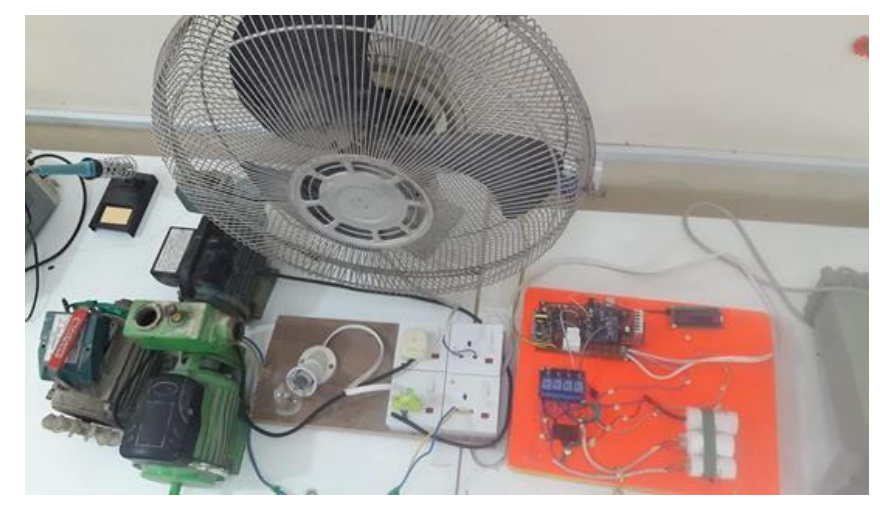

Figure 9. Implementation of the proposed APFC circuit

Table 2. Capacitors Range with Their Corresponding Error

\begin{tabular}{cccc}
\hline Error $=\left|\frac{\text { Theoretical-Practical }}{\text { Theoretical }}\right| *$ & $\begin{array}{c}\text { Practical Capacitor } \\
\text { Value }(\mu \mathrm{F})\end{array}$ & $\begin{array}{c}\text { Theoretical Capacitor } \\
\text { Value }(\mu \mathrm{F})\end{array}$ & PF levels \\
\hline $00 \%$ & 0 & 0 & Above 0.98 \\
4.1 & 2.5 & 2.4 & $0.98-0.9585$ \\
4.1 & 5 & 4.8 & $0.9585-0.9375$ \\
4.1 & 7.5 & 7.2 & $0.9375-0.91625$ \\
4.1 & 10 & 9.6 & $0.91625-0.895$ \\
4.1 & 12.5 & 12 & $0.895-0.87375$ \\
4.1 & 15 & 14.4 & $0.87375-0.8525$ \\
4.1 & 17.5 & 16.8 & $0.8525-0.83125$ \\
4.1 & 20 & 19.2 & $0.83125-0.81$ \\
4.1 & 22.5 & 21.6 & $0.81-0.78875$ \\
4.1 & 25 & 24 & $0.78875-0.7675$ \\
4.1 & 27.5 & 26.4 & $0.7675-0.74625$ \\
4.1 & 30 & 28.8 & $0.74625-0.725$ \\
4.1 & 32.5 & 31.2 & $0.725-0.70375$ \\
4.1 & 35 & 33.6 & $0.70375-0.6825$ \\
4.1 & 37.5 & 36 & $0.6825-0.66125$ \\
2.3 & 37.5 & 38.4 & $0.66125-0.64$ \\
2.3 & 37.5 & 38.4 & Less than 0.64 \\
\hline
\end{tabular}

As can be seen from Table 3, the resulting PF approaches the desired value (0.98) but not really equal it, since there is somehow an error, but it is still stable and close to the desired value. In other words, there is an error, and comes from two sources, the first one is due to the inserted capacitor that is not really equal to the desired capacitor, as depicted from calculations (5-8). How to solve this problem or reduce this error is by choosing a value of a capacitor closing to the desired one. 
Table 3. PFC Results with Different Load

\begin{tabular}{|c|c|c|c|c|}
\hline \multicolumn{4}{|c|}{ After correction } & \multirow{2}{*}{$\frac{\text { Before correction }}{\mathrm{V}(\mathrm{v})}$} \\
\hline $\mathrm{PF}$ & $\mathrm{PF}$ & $\mathrm{I}(\mathrm{A})$ & $\mathrm{P}$ (watt) & \\
\hline 0.94 & 0.79 & 3.61 & 613.1 & 214 \\
\hline 0.95 & 0.75 & 2.54 & 407.87 & 214 \\
\hline 0.96 & 0.68 & 1.9 & 277.78 & 214 \\
\hline 0.94 & 0.63 & 1.25 & 169.28 & 215 \\
\hline 0.94 & 0.74 & 0.75 & 115.35 & 216 \\
\hline 0.96 & 0.85 & 0.7 & 129.54 & 216 \\
\hline 0.97 & 0.87 & 1.08 & 201.99 & 214 \\
\hline
\end{tabular}

The second source of error is due to the difference between the practical corrected power factor and the desired one. This comes from the theoretical calculations that use $2^{4}$ correction levels (ranges) of PF. The difference between theoretical and practical results (error) can be shown in Table 4. This error can be reduced by increasing the number of branches (ranges) to 7 or 8 of branch capacitor.

Table 5. Error Between the Corrected and Desire Power Factor

\begin{tabular}{ccccc}
\hline Error & Desired Pf & Corrected Pf & Original Pf & Power(w) \\
\hline $4.08 \%$ & 0.98 & 0.94 & 0.7 & 545.65 \\
$3 \%$ & 0.98 & 0.95 & 0.69 & 332.6 \\
$2 \%$ & 0.98 & 0.96 & 0.68 & 264 \\
$4.08 \%$ & 0.98 & 0.94 & 0.74 & 106.3 \\
$1 \%$ & 0.98 & 0.97 & 0.87 & 171.3 \\
$2 \%$ & 0.98 & 0.96 & 0.66 & 270 \\
\hline
\end{tabular}

In addition, you can see from the variation of error against the original PF that depicted in Figure 10, the error increases when the power factor is in the range from 0.7 to 0.8 , and decreases whenever the PF closes to the desired value. Finally, in spite of that, the error is very small, and could be neglected since the system works very well and gives stable results in different loads having different PF.

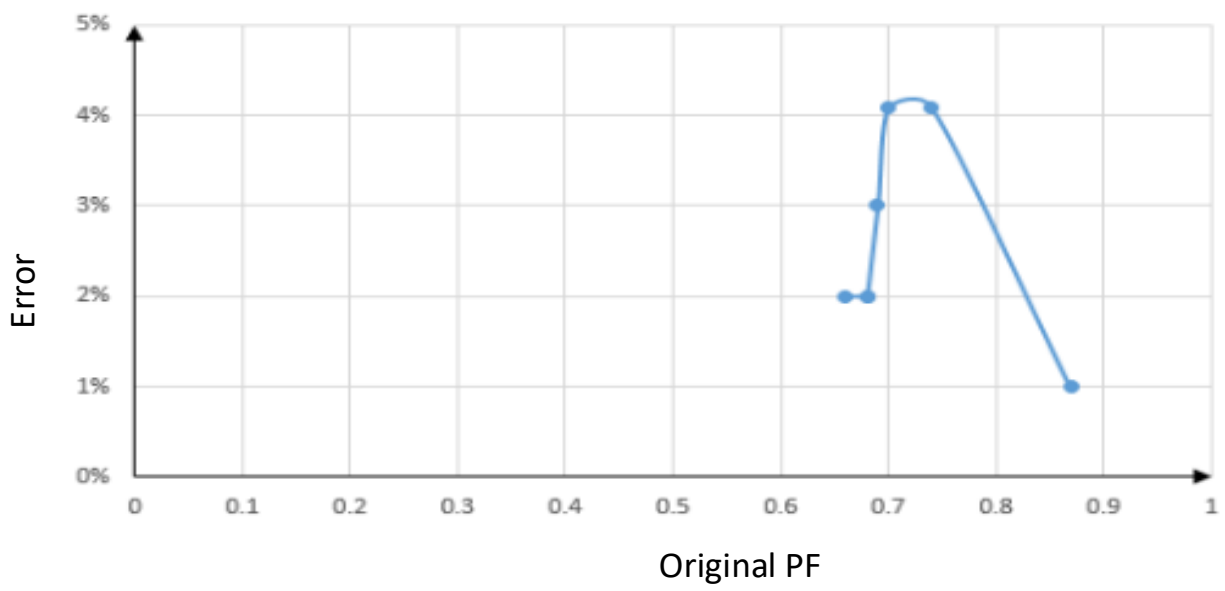

Figure 10. Error variation in proposed PFC system

As compared to [14] A. Taye, the searcher corrected the PF for the range from 0.66 to 0.92 , while here in this research the $\mathrm{PF}$ is corrected for the range 0.64 to 0.98 with acceptable error. Also in this work, the maximum error obtained is $4.08 \%$ for different loads, while as compared to [13] the maximum error is $20.54 \%$ in spite of the work depends on the capacitor that found at the market, while [13] depends on the simulated capacitor value. 


\section{COCLUSION}

In this paper, an Automated Power Factor Correction system is proposed and implemented to serve a small office or house by using a Current Transformer, Voltage divider, Arduino microcontroller, Relays, and Four capacitors with LCD to display all readings. Therefore, the system has a very little cost as compared with the work one placed in the generation station. The Arduino is responsible of the decision of what capacitor to work and the Fuzzy program speeds the system and make the decision more accurate, also, it works the device in real time. The system works with sixteen level of correction from 0.64 to 0.98 with load up to $1000 \mathrm{VA}$.

It can be concluded from the results that the system operation is stable, and it has very good results with no time delay and small error. In addition, there are two types of error, the first one is due to the capacitor that added is not equal exactly to the desired capacitor, causing a maximum error of $4.1 \%$. The second one is due to the difference in PF readings (desired and result PF), producing a maximum error of $4.08 \%$ in the range from 0.7 to $0.8 \mathrm{PF}$. The error can be reduced to zero by adding additional capacitors through increasing the level of correction to 32 or 64.

\section{REFERENCES}

[1] O. Krejcar and R. Frischer, "Real Time Voltage and Current Phase Shift Analyzer for Power Saving Applications", Sensors, pp 11391-11405, 2012.

[2] P. Sonje, P. MTech and B. Vidyapeeth, "Power Factor Correction Using PIC Microcontroller", International Journal of Engineering and Innovative Technology (IJEIT), Volume 3, Issue 4, pp 272-276, October 2013.

[3] G. Premkumar and B. Muthkumar, "Design, Fabrication and Implementation of Microcontroller Controlled Static Var Compensator", International Journal of Computer Applications, Volume 81, No 19, pp 43-50, November 2013.

[4] R. S. Biswas and S. Mal, "Automatic power factor improvement using microcontroller", International Conference and Workshop on Computing and Communication (IEMCON), IEEE conference, Canada, 2015.

[5] Y. Kabir, Y. M. Mohsin and M. M. Khan, "Automated power factor correction and energy monitoring system", Second International Conference on Electrical, Computer and Communication Technologies (ICECCT), IEEE conference, India, 2017.

[6] K. Tiwari, D. Sharma, V. K. Sharma, "Automatic Power Factor Correction Using Capacitive Bank", International Journal of Engineering Research and Applications, Vol. 4, Issue 2, pp. 393-395, February 2014.

[7] S. Padmawar and A. Wanare, "Power Factor Correction based on PWM waves using PIC", International Journal of Innovative Science, Engineering \& Technology, Vol. 1, Issue 6, pp. 94-97, August 2014.

[8] V. Praveen, S. Fathima, I. Sumalata, K. Badiger and S. Kandagal, "Automatic Power Factor Correction Using Capacitor Banks and 8051 microcontroller", International Journal of Engineering and Technical Research (IJETR), Volume-3, Issue-6, pp 163-167, June 2015.

[9] M. C. Mary, D. R. BeninManoRaja, S. S. Kumar and M. Govinathan, "Microcontroller Based Automatic Power Factor Correction", International Journal of Innovative Research in Science, Volume 4, Special Issue 4, pp. 72-75, April 2015.

[10] M. Vishvanath, R. Balamurugan, "An Review of Power Factor Correction in SRM Drives Using Bridgeless Converters", TELKOMNIKA Indonesian Journal of Electrical Engineering, Vol. 14, No. 3, June 2015, pp. $441-445$.

[11] Murugan M, Jeyabharath R and Sarankumar V, "An Approach of PFC in BLDC Motor Drives Using BLSEPIC Converter", TELKOMNIKA Indonesian Journal of Electrical Engineering, Vol. 14, No. 2, May 2015, pp. $215-221$.

[12] R. Pireethi and R. Balamurugan, "Bridgeless Isolated Cuk PFC Implementation using PID and Neural Controller", Indonesian Journal of Electrical Engineering and Computer Science, Vol. 2, No. 1, April 2016, pp. $88 \sim 95$.

[13] M. M. Than, "Implementation of Power Factor Correction Using Solid State Switched Capafcitors", Journal of Electrical and Electronics Engineering (IOSR-JEEE), Volume 11, Issue 4, Ver. II, pp. 70-79, Jul. - Aug. 2016.

[14] A. Taye, "Design and Simulation of Automatic Power Factor Correction for Industry Application", International journal of Engineering Technology and Management Research, Volume 5, Iss. 2, pp. 11-21, February 2018.

[15] S. Q. Li, L. Y. Yuan, "Design of Fuzzy Logic Missile Guidance Law with Minimal Rule Base", Sixth International Conference on Fuzzy Systems and Knowledge Discovery, IEEE conference, China, 2009.

[16] P. Singhala, D. N. Shah, B. Patel, "Temperature Control using Fuzzy Logic", International Journal of Instrumentation and Control Systems, Vol.4, No.1, pp. 1-10, January 2014.

[17] R. Dhameliya, K. Domadiya, P. Miyani and H. Savaliy, "Automatic Power Factor Control using Arduino Uno", International Journal of Advance Engineering and Research Development, Volume 4, Issue 4, pp. 270-276, 2017.

[18] W. Ali, H. Farooq, M. Jamil, A U. Rehman, R. Taimoor, and M. Ahmad, "Automatic Power Factor Correction for Single Phase Domestic Loads by Means of Arduino Based TRIAC Control of Capacitor Banks", $2^{\text {nd }}$ International Conference on Energy Conservation and Efficiency (ICECE), IEEE conference, Lahore, Pakistan, 2018. 


\section{BIOGRAPHIES OF AUTHORS}
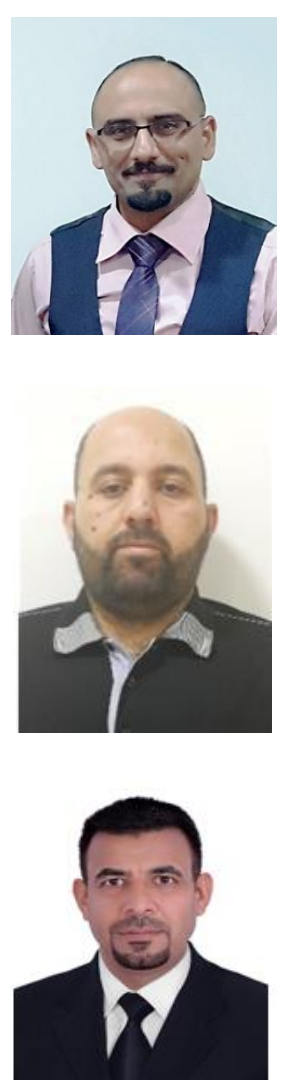

Osama Qasim Jumah Al-Thahab: The author was born in Iraq, Babil, AlHilla City, Al-Tayara Quarter 1978. He received the B.Sc. from Babylon University in General Electrical Engineering 2000. The M.Sc. and Ph.D. are in Electronics and Communications field from University of Technology-Iraq 2003 and 2007 respectively. Since 2014, he has been an Assistant Professor with the Electrical Engineering Department, Babylon University. The fields that the Author interested are, Microcontroller, Image Processing, Quad Copter, Home Automation, Speech analyzing, Digital design, etc. Also until know he has 10 articles in these fields.

Ali Shaban Hassooni: He born in Babil, Iraq 1981. He achieved B.S.c. since 2003 in Electrical Engineering, College of Engineering, Universty of Babylon, Iraq and He achieved M.S.c. in Electronics and Communication field since 2010 in Electrical Engineering, College of Engineering, Universty of Babylon, The main interested field is designing of electronics system and robotics fileld. He is a Lecturer in Electrical Engineering Department, College of Engineering, Babylon University, Iraq.

Mr. Ahmed Samawi Alkhafaji earned his M.sc in the field of Electrical and Electronic Engineering from Eastern Mediterranean University, Turkey / North Cyprus2013. He has more than five years of experience in teaching. He completed his BSc in Electrical Engineering, university of technology, Baghdad, Iraq, 2001. His research interests includes power electronics, control power system, electronic system design and predictive current control modeling. 